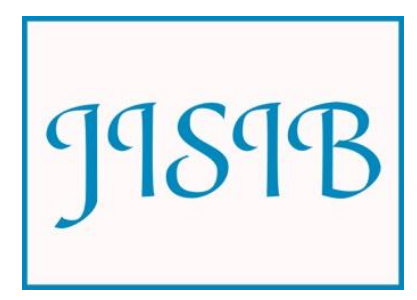

Available for free online at https://ojs.hh.se/

Journal of Intelligence Studies in Business 1 (2011) 107-127

\title{
Key Success Factors in Business Intelligence
}

\author{
Szymon Adamala * and Linus Cidrin ** \\ * Business Intelligence and data warehousing consultant, Poland, \\ szymon.adamala@gmail.com \\ ** Management consultant, Sweden, \\ linus.cidrin@hotmail.com
}

Received 25 May 2011; received in revised form 3 June 2011; accepted 25 November2011

\begin{abstract}
Business Intelligence can bring critical capabilities to an organization, but the implementation of such capabilities is often plagued with problems. Why is it that certain projects fail, while others succeed? The aim of this article is to identify the factors that are present in successful Business Intelligence projects and to organize them into a framework of critical success factors. A survey was conducted during the spring of 2011 to collect primary data on Business Intelligence projects. Findings confirm that Business Intelligence projects are wrestling with both technological and non-technological problems, but the non-technological problems are found to be harder to solve as well as more time consuming than their counterparts. The study also shows that critical success factors for Business Intelligence projects are different from success factors for Information Systems projects in general. Business Intelligences projects have critical success factors that are unique to the subject matter. Major differences can be found primarily among non-technological factors, such as the presence of a specific business need and a clear vision to guide the project. Success depends on types of project funding, the business value provided by each iteration in the project and the alignment of the project to a strategic vision for Business Intelligence at large. Furthermore, the study provides a framework for critical success factors that, explains sixty-one percent of variability of success for projects. Areas which should be given special attention include making sure that the Business Intelligence solution is built with the end users in mind, that the Business Intelligence solution is closely tied to the company's strategic vision and that the project is properly scoped and prioritized to concentrate on the best opportunities first.
\end{abstract}

Keywords: Business Intelligence, Data Warehouse, Critical Success Factors, Enterprise Data Warehouse, Success Factors Framework, project risk management

\section{Introduction}

This article originated from a Master' $\mathrm{s}$ Thesis that the authors wrote as part of their MBA studies at Blekinge Institute of Technology, supervised by Dr. Klaus Solberg Søilen.

The aim of the article is to develop the tools necessary to analyze, predict and manage the success of Business Intelligence, data warehousing and competitive intelligence initiatives in contemporary organizations. "There is no reason that each organization, as it begins and continues to develop data warehouse projects, must wrestle with many of the very difficult situations that have confounded other organizations. The same impossible situations continue to raise their ugly heads, often with surprisingly little relation to the 
industry, the size of the organization, or the organizational structure" (Adelman, 2003). If there is indeed little correlation between success and the environmental factors of those initiatives, the cause of success must be related to something else. It is worth investigating whether the difficulty, complexity of initiatives and the high probability of failure are related to some factors inherent to Business Intelligence itself.

In fact, most of the Business Intelligence and data warehouse projects fail and the failure rate is estimated to be between 50-80\% (Beal, 2005; Meehan, 2011; Laskowski, 2001; Legodi \& Barry, 2010). Why do so many of these projects fail? " The warehouse is used differently than other data and systems built by information systems" (Inmon, 2002). Therefore, the available knowledge on how to manage ordinary projects in the information systems domain should not be expected to be readily applicable to the area of Business Intelligence.

Our initial information search revealed that Business Intelligence has been covered in a large number of academic articles and books. However, Business Intelligence success is not widely treated. Few articles attempt to analyze what the factors are which influencing BI. Some of them have developed frameworks, but there is no proven framework that can be relied upon for this particular problem.

The success of BI initiatives undertaken by companies depends on various factors. Because BI implementation depends on the successful use of IT resources, some of those factors are undoubtedly technological. However, Information Technology is merely a tool in implementing a BI solution. BI success depends chiefly on organizational and process factors that business administration focuses on. Despite differences in BI systems between various industries, those factors should be identified and classified. The existence of a link between individual factors or their combinations and the success of BI initiatives should be verified. Moreover, success factors could be classified and a method of measurement could be devised for each individual factor. As the management thinker Peter Drucker once said, "what gets measured, gets managed". Currently, BI initiatives have a relatively low success ratio. The successful ones achieve ROI in excess of $400 \%$ (according to some vendors). This figure is even more impressive when taking into account the (traditionally capital) investments in the infrastructure and equally high (traditionally operational) expenses on development projects, operations, consulting services etc. An ability to assess the chances of success prior to engaging in the initiative would have two practical benefits:
1. Preventing some of the initiatives from commencing if they score low in the framework of success factors or allowing them to focus on critical issues that otherwise would have caused a failure - as a result, the success ratio of all BI initiatives improves.

2. Facilitating management of the investment in Business Intelligence and lowering the entry barriers (given the high level of investment, $50 \%$ probability of failure might be too high for smaller companies if the loss resulting from failure push the company into bankruptcy).

The article focus on the following hypotheses:

Hypothesis 1. It is possible to identify critical success factors (CSFs) of BI initiatives and they are different from the CSFs of information systems (IS) in general.

Hypothesis 2. Non-technical and non technological CSFs play a dominant role in BI initiatives' success.

Hypothesis 3. Technology plays a secondary role and is less critical for BI initiatives' success.

Hypothesis 4. It is possible to develop objective measures for each of CSFs of $\mathrm{BI}$ initiatives.

If the abovementioned hypotheses can be proved, CSFs of BI initiatives can create a framework that can be used to predict the success in early stages of $\mathrm{BI}$ initiatives.

It should be noted that, even though this study is primarily focused on vendors in Poland, the conclusions from this study may have relevance and be applicable to other countries as well, especially since many of the companies studied were global enterprises and other aspects of projects and IT are global: Outsourcing, offshoring, nearshoring and other forms of international operations. the differences in survey results between Poland and other countries were not significant and drawing conclusions from the sample we gathered, we claim that our findings are also applicable to Business Intelligence projects in larger enterprises worldwide. The reason for choosing Poland as the primary country is that one of the authors has been working there for many years and had good access to empirical data.

There is some ambiguity around the use of the terms data warehouse and Business Intelligence among practitioners. Historically, data warehousing meant "the overall process of providing information to support business decision making" (Kimball, Ross, Thornthwaite, Mondy \& Becker, 2008, p. 10). Following these authors, "delivering the entire end-to-end solution, from the source extracts to the queries and applications that the 
business users interact with" (Kimball et al.,2008, p. 10) has always been a fundamental principle. However, the term Business Intelligence coined in the 1990s meant only reporting and analysis of data stored in the warehouse, effectively separating the two terms. Even now, there is no agreement in the industry - some "refer to data warehousing as the overall umbrella term, with the data warehouse databases and BI layers as subset deliverables within that context" (Kimball, et al., 2008, p. 10), while others "refer to business intelligence as the overarching term, with the data warehouse relegated to describe the central data store foundation of the overall business intelligence environment" (Kimball et al., 2008, p. 10).

Because the aim of this article is not to define the term of Business Intelligence, but rather to investigate its success factors, both conventions are accommodated. The literature referring both to data warehouse systems/projects and Business Intelligence systems have been reviewed. There is no difference in their relevance to our study, especially when taken into account the industry practice that even "though some would agree that you can theoretically deliver BI without a data warehouse, and vice versa, that is ill-advised $/ \cdots /$. Linking the two together in the DW/BI acronym further reinforces their dependency" (Kimball et al., 2008, p. 10). Despite this argumentation, Business Intelligence is used in this article as an overall term.

The research is concentrated mainly on the factors that lead to the success of BI initiatives, cause its success (or are able to prevent it), or are otherwise correlated with the success. However, little attention is paid to the definition of the success itself or its measurement. According to Delone and McLean (1992; 2003), success in business entails net benefits. To properly define success, those net benefits need to be measured. The authors' goal of obtaining objective measurement criteria would call for a method to compute the NPV of a BI initiative. A similar subject (without the emphasis on BI, but rather for software in general) has recently been a topic of a $\mathrm{PhD}$ thesis at Blekinge Institute of Technology (Numminen, 2010). Clearly, calculating the NPV of BI initiatives will be out of scope for this article. Therefore, the success itself will not be defined as clearly as the authors should want to at first. This would instead be a suggestion for further research in this area.
Several of the models proposed in the literature (Delone \& McLean, 1992; 2003; Hwang $\& \mathrm{Xu}, 2008$; Wixom \& Watson, 2001) analyze the interdependency between independent variables. Furthermore, none of the abovementioned authors propose a direct correlation with success for those variables that were used to explain variability of other independent variables. The goal of this study is to enumerate all the CSFs of BI projects, not to analyze how they depend on each other. For each of the independent variables analyzed, a direct dependency between success and that variable is analyzed.

\section{Literature review}

Dr Ralph Kimball is credited with developing arguably the most successful data warehouse architecture, the dimensional modeling. The success criteria as described by Kimball are named

"readiness factors". The author suggests giving up the initiative, if some of the criteria are missing or insufficient. "Readiness shortfalls represent project risks; the shortfalls will not correct themselves over time. It is far better to pull the plug on the project before significant investments have been made than it is to continue marching down a path filled with hazards and obstacles" (Kimball R., Ross, Thornthwaite, Mondy, \& Becker, 2008, p. 16).

Let us examine the existing frameworks that might be applicable for explaining Business Intelligence success.

\subsection{Information Systems Success}

The most obvious first choice when trying to discover BI success factors is to look at information systems (IS) in general. There exists an excellent framework proposed by Delone and McLean (Delone \& McLean, 1992; 2003) that has been widely cited, revisited, criticized, validated or extended in hundreds of articles (Delone \& McLean, 2003). The original framework proposed by Delone and McLean (1992) has been reexamined in the light of that subsequent research, resulting in a slightly updated version (Delone \& McLean, 2003) that will be discussed here. The proposed framework defines IS success in terms of system use, user satisfaction and net benefits whereas the factors leading to the success encompass information quality, system quality and service quality. The interdependences between those variables are depicted in Figure 1. 


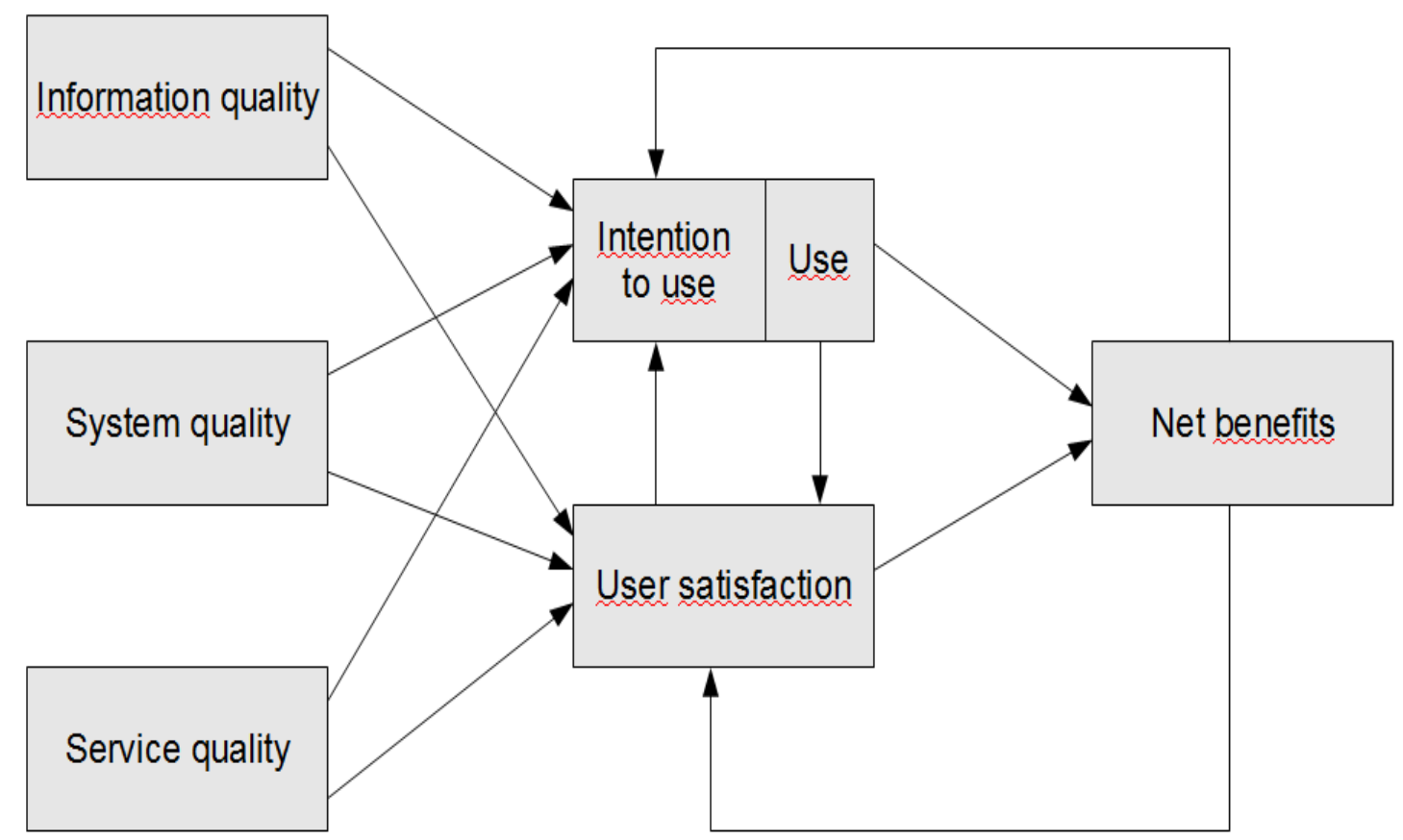

Figure 1: Delone\&McLean model for IS success (Delone \& McLean, 2003)

Our study did not measure system quality and service quality at all, as they are inapplicable to Business Intelligence. As Solberg Søilen and Hasslinger (2009) found, vendors of BI tools do not differentiate their products and tools (other than adopting different definitions of Business Intelligence). Therefore, system quality should not be a factor in the Business Intelligence domain. Because Business Intelligence systems are built to present data and facilitate its analysis, data quality is probably the most important factor. From the " second tier" variables, intention to use and user satisfaction should play a small role in Business Intelligence. If BI is tied to strategic vision for the entire company, users are obliged to use the solution and not their own data sources. Therefore, use alone as a variable plays a role.

One major drawback with this framework that we identified is the concentration on technology. The findings of our research dictate that the success of BI initiatives relies on numerous factors that are within the management domain rather than on technological factors. Therefore, although the Delone and McLean model of IS success has been applicable to many specific information systems, even those that have been unforeseen when the framework was originally constructed (Delone \& McLean, 2003), we think it cannot be applied to Business Intelligence systems without due changes.

Delone and McLean's framework not only does not propose any specific measurement methods, but also avoids specific variable definitions, leaving them to be concretized at the time of framework application, depending on the specific context (Delone \& McLean, 2003).

\subsection{Critical Success Factors for BI Systems}

"The implementation of a BI system is not a conventional application-based IT project (such as an operational or transactional system), which has been the focus of many CSF studies" (Yeoh \& Koronios, 2010). Having noted that, the authors proceeded to propose a framework that included some of the critical success factors or success variables from Delone \& McLean (1992) as a part. System quality, information quality and system use were grouped together and labeled "infrastructure performance". As an equal factors group, process performance was proposed, encompassing classical project management variables like budgets and time schedules. The authors emphasized a different set of factors, divided into three broad categories organization (vision and business case related factors, management and championship related factors), process (team related factors, project management and methodology related factors, change management related factors) and technology (data related factors, infrastructure related factors). All those factors cause business 


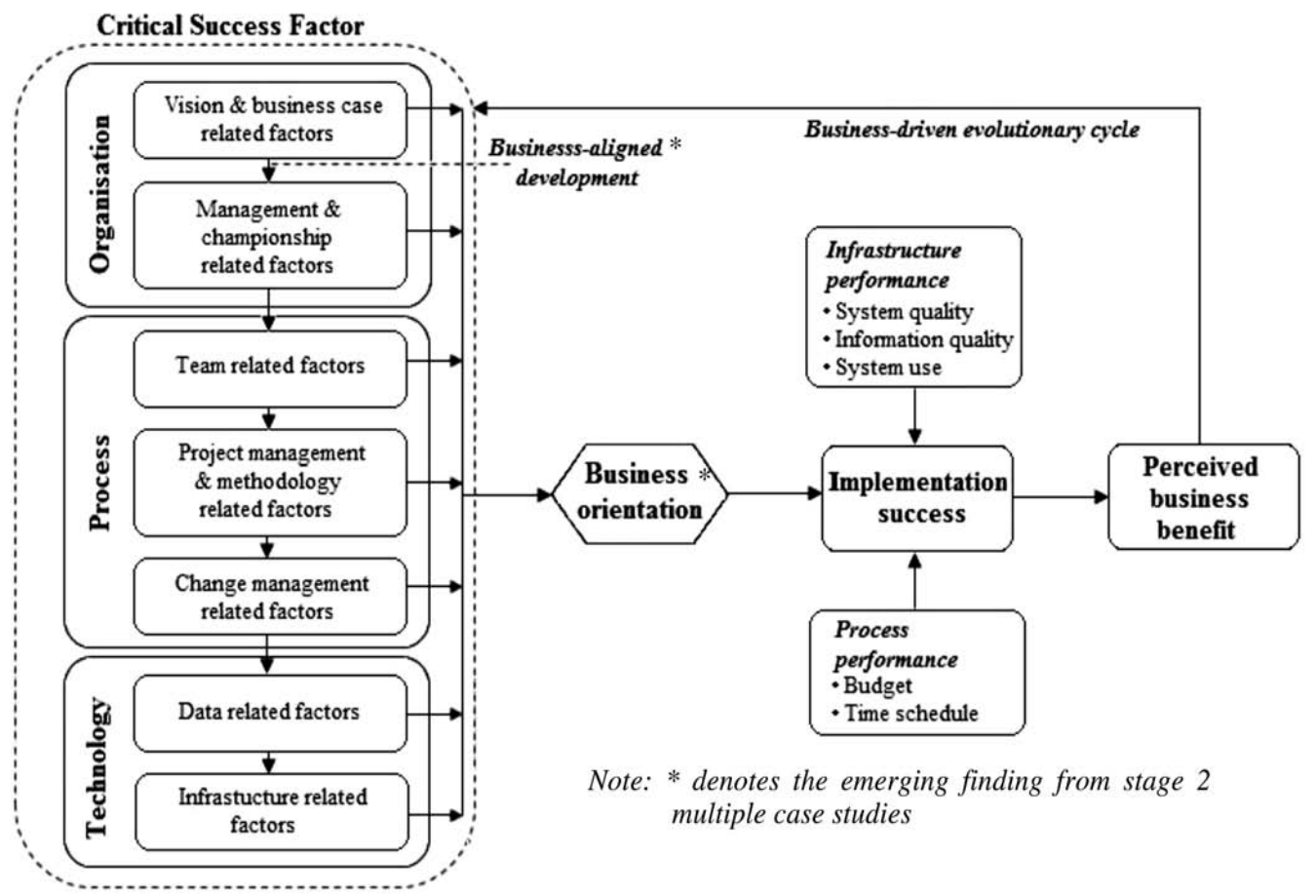

Figure 2: Yeoh \& Koronios model of success in BI (Yeoh \& Koronios, 2010)

orientation, which in turn, together with before mentioned infrastructure and process performance factors lead to implementation success and, subsequently, to perceived business benefit. This framework is illustrated in Figure 2.

A summary of success factors across all the dimensions with the highlight of the most important points:

\section{Organizational dimension}

- Committed management support and sponsorship

- Clear vision and well-established business case

Process dimension

- Business-centric championship and balanced team composition

- Business-driven and iterative development approach

- User-oriented change management

Technological dimension

- Business-driven, scalable and flexible technical framework

- Sustainable data quality and integrity

This framework is considerably better suited for Business Intelligence systems than the one presented by Delone and McLean (2003). However, it has a few drawbacks. First, there are no specific measurement criteria proposed. Since several of the variables are defined in a way so that very different measurement criteria can be defined or it would be hard to devise measures other than the Likert scale, the framework would be impractical to apply and the results might depend on the subjective opinions of those that provide or calculate variable' $s$ values, resulting in the false prediction of BI initiative success. Another drawback is an artificial reliance on the Delone and McLean (2003) model of IS success. Some infrastructure performance factors (system quality, information quality) belong under the technology category (infrastructure related factors or data related factors) and should not be repeated at all or the causal dependency should be included in the framework.

Further criticism of this article (Yeoh \& Koronios, 2010) can be based on the way inclusion of technology related factors was performed. Business-driven, scalable and flexible technical framework" and particular variables that fall into this category are too close to the way the vendor who delivered the solution gives advice on his or her product. Also, the fact that this article (Yeoh \& Koronios, 2010) was based on a single project 
plays down the objectivity of its findings. As our survey later revealed, technical issues are of secondary importance.

\subsection{Impossible Data Warehouse Situations.}

Why are the success criteria so important? As we have already mentioned in the introduction, some data warehouse implementations fail. It is possible that many of these 'failures' would be considered successes (or at least to be positioned someplace between failure and success). The criteria for success are often determined afterwards. This is a dangerous practice since those involved with the project don' t really know their targets and will make poor decisions about where to put their energies and resources (Inmon, 2002).

According to Adelman (2003), the example measures of success include the following elements:

- The data warehouse usage.

- Usefulness of the data warehouse, including end user satisfaction.

- Acceptable performance as perceived and experienced by end users.

- Acceptable ROI - benefits justifying the costs.

- Relevance of data warehouse application.

- Proper leverage of a business opportunity (i.e. establishing competitive advantage thank to the application of data warehouse).

- Timely answers to business questions.

- Higher quality / cleanliness of data (than in the source systems).

- Initiation of changes in the business processes that can be improved as a result of the use of data warehouse (Adelman, 2003, p. $5 \& 40)$.

Douglas Hackney emphasized the critical importance of establishing success measures - “ The 'build it and they will come' approach (*) does not work in data warehousing" (Adelman, 2003, p. 41). He further suggests starting with business "pain" with the available data. The words "life-threatening" seem to accurately describe the problem that need to be chosen to solve (Inmon, 2002, p. 41). An example of a business "pain" might be the "loss of revenue or excessive operating costs" (Inmon, 2002, p. 42).

The main theme of the book of Adelman (2003) is not the success factors of Business Intelligence initiatives. Instead, the author concentrates on various difficult situations and proposes methods to overcome those adversities. Although he does not name those factors as influencing the success itself, some of them should at least be evaluated for possible inclusion in the final framework of this study. According to the author, all difficulties can be organized in one of the following categories (the first seven represent management issues, the rest is concerned with the technical side):

1. Management issues

2. Changing requirements and objectives

3. Justification and budget

4. Organization and staffing

5. User issues

6. Team issues

7. Project planning and scheduling

8. Data warehouse standards

9. Tools and vendors

10. Security

11. Data quality

12. Integration

13. Data warehouse architecture

14. Performance

From the factors identified in the book of Adelman (2003), we found a few that were less important than others, while some were not considered at all in our survey as separate variables. For example, architecture, performance, security, tools and standards were considered as one broad variable technical issue in our research and were deemed of secondary importance. Data quality, on the other hand, was measured in our survey separately for source systems and target solution, both being found to have importance.

Adelman ( 2003) devote at least equal attention to technical issues in general as to all nontechnical issues, the latter being mentioned in less detailed discussions. Broad and general categories of "user issues", "team issues" , organization and staffing" etc. make detailed comparison with our study difficult. Also, a different terminology plays a role here. What the author considers measures, our study call variables. For example, "data warehouse usage" was a measure in the book (Adelman, 2003) while as we propose three distinct measurement methods, namely number of queries per period, number of logons per period and number of users per period.

\subsection{Competing Value Model}

Since different stakeholders will look at different criteria to determine if the initiative was a successful one, different perspectives may need to be taken into account. This issue of potentially conflicting criteria has been discussed by Walton and Dawson in their Competing Value Model which organizes criteria in different dimensions (Walton \& Dawson, 2001). This could be present in BI initiatives as well, where different 
stakeholders can have different non-overlapping criteria for success; for example a system integrator can have different objectives for engaging in a BI initiative, different from the end user organization (the customer).

This study did not attempt to define BI initiative success, but considered using this kind of classification of criteria for different dimensions, such as technical and non-technical. The definition of success of BI initiatives is not part of this study. One consequence of the findings of the article by Walton \& Dawson (2001) is that the development of a framework allows for the interest of different stakeholders to be organized. This problem is left for future studies.

\subsection{A Critical Success Factor Framework for Implementing Business Intelligence Systems}

Qualitative studies have been used in the area of critical success factors in Business Intelligence many times. One of these is a Critical Success Factor Framework for Implementing Business Intelligence Systems (Yeoh, Gao, \& Koronios, 2007) where the authors performed a Delphi study covering $15 \mathrm{BI}$ systems experts to define a critical success factor framework for implementing business intelligence systems. The authors propose a framework that is organized into seven dimensions covering 22 factors. The seven dimensions of this article (Yeoh, Gao, \& Koronios, 2007) are:

- Commitment management support and championship

- User-oriented change management

- Business vision

- Project planning

- Team skills and composition

- Infrastructure-related dimensions

- Data related issues

The Delphi panel rates the factors in those dimensions and a mean is calculated for each dimension. The above list of dimensions is ordered in a falling mean ranking, starting with the dimension with the highest rating. We see that more technical dimensions can be found at the very bottom of the list, while as non-technical dimensions are found higher up in the list.

The paper by Yeoh et al. (2007) demonstrates, in line with the result from this study, that management championship and the presence of a clear vision for Business Intelligence is important when executing a Business Intelligence initiative. While the result from this study seems to indicate that the technical factors are more important than the non-technical factors, the authors of the paper include two "technical" dimensions out of seven. It should be said that the ratings of the two technical dimensions are the lowest out of the seven, which is well in line with the findings of this study.

\subsection{Risk Management in Enterprise Data Warehouse Projects in South Africa}

The paper starts with the claim that data warehousing implementation projects have high estimated failure rates, up to about $50 \%$ (Legodi \& Barry, 2010). The objective of the paper and the study was to investigate the main areas of risk for these projects, and a Delphi method was used for the data collection. The study was performed in South Africa. Results from the study are in the form of the main problems and the success factors for this type of project. The identified factors that have the greatest impact on success from the study (Legodi \& Barry, 2010) are (listed in priority order):

1. Scope Creep

2. Uncontrolled Finances

3. Poor Communication

4. Stake Holder Non-Involvement

5. Skills Shortage

6. Unavailability of Tools and Technology

7. Uncontrolled Quality of Deliverables

8. Poor, Wrong or No Leader

9. Technical Difficulties

10. Legal Difficulties

We note that the first technical difficulties can be found in the ninth item.

(Legodi \& Barry, 2010) show, like the results from this study, that non-technical factors affect the success of a project the most. Out of the ten factors Legodi and Barry (2010) identified, only one were of technical nature and placed as the ninth factor (technical difficulties). The fourth item, stakeholder non-involvement, can be comparable to the importance of vision and addressing a specific business need of the sponsor. While the paper surveyed a more narrowly defined geography (South Africa), the finding that non-technological factors dominate is shared between that paper and this study.

\subsection{An Exploratory Investigation of System Success} Factors in Data Warehousing

The variables used in a study by Shin (2003) are system throughput, ease of use, ability to locate data, access authorization, data quality (subdivided into 4 more detailed categories of recency/currency, level of detail, accuracy and consistency), information utility, user training and user satisfaction, with the latter is being used as dependent variable. The data was gathered from a single large US enterprise, based on a single 
project, therefore even the author agrees that this study must be treated as a case study (Shin, 2003, p. 157). The authors found that $70 \%$ of end user satisfaction could be explained by the independent variables that were measured.

Shin (2003) approaches data warehousing success in a different way than in the above study, treating end user satisfaction as a proxy for project success. This is also inconsistent with Delone and McLean approach (Delone \& McLean, 1992; 2003) which Shin cited and claimed to be "the most influential model in conducting research on information systems success factors" (Shin, 2003, p. 144). The variables used are mainly different from the inspected ones, with only data quality being common with this study. Variables used by Shin (2003) describe predominantly technological factors. As in this study actual use is only one of the variables, the results are hardly comparable. Also, a case study approach concentrated on success within just one company makes this article (Shin, 2003) less valuable for creating a larger data warehousing or Business Intelligence success criteria framework.

A Structural Model of Data Warehousing Success by Hwang \& Xu (2008) analyzes several factors influencing data warehousing success. Success is not measured as a separate variable. Instead, following Delone and McLean (1992; 2003), benefits and quality are used as proxy, with a distinction between individual and organizational benefits as well as system and information quality. The independent variables are; operational factor, technical factor, schedule factor and economic factor. The authors propose at least two measures for each variable, dependent and independent. The model (Figure 3) is able to explain between 27\% (system quality) and $41 \%$ (organizational benefits) of the dependent variables variability.

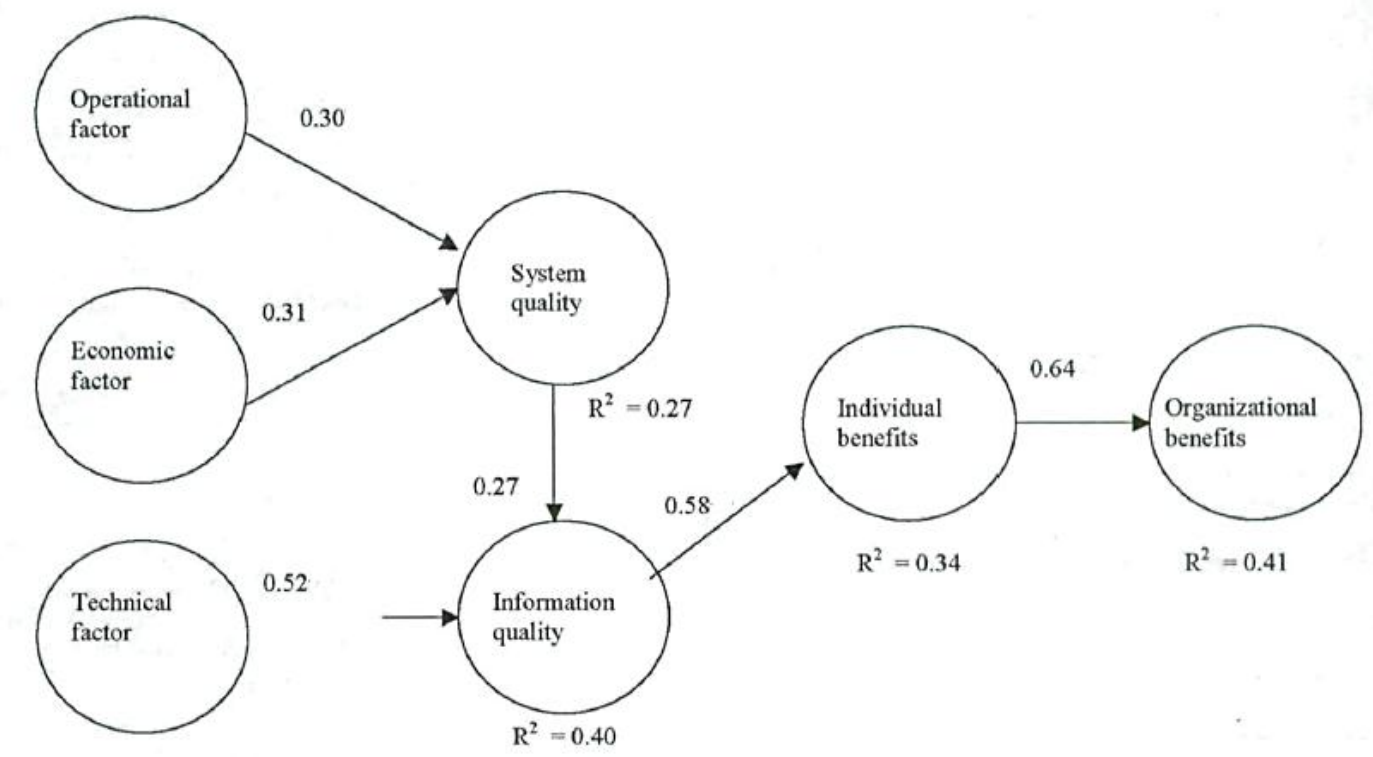

Figure 3: Hwang \& Xu structural model of data warehousing success (Hwang \& Xu, 2008)

The most prominent difference in approaches is the definition of what a variable is and what a measure is. Many measures from this article (Hwang \& $\mathrm{Xu}$, 2008) are variables in our study, for example business benefits definition, business benefits measurability or scoping of a project. The aim for objective measurement methods were not one of the goals of Hwang \& Xu (2008) and it is unclear how measures proposed in their work should be performed in practice. The authors were overly reliant on the model of IS success (Delone \& McLean, 1992; 2003), obtaining little explanatory power for their model. From the way the model was constructed, it is also hard to compare whether technical or non-technical factors play major role in data warehousing success.
An Empirical Investigation of the Factors Affecting Data Warehousing Success (Wixom \& Watson, 2001) examined the factors influencing data warehousing success. Authors verified several hypotheses. Findings can be summarized as follows:

Hypothesis 1a. A high level of data quality will be associated with a high level of perceived net benefits (supported).

Hypothesis 1b. A high level of system quality will be associated with a high level of perceived net benefits (supported).

Hypothesis 2a. A high level of organizational implementation success is associated with a high level of data quality (not supported). 
Hypothesis 2b. A high level of organizational implementation success is associated with a high level of system quality (supported).

Hypothesis 3a. A high level of project implementation success is associated with a high level of data quality (not supported).

Hypothesis 3b. A high level of project implementation success is associated with a high level of system quality (supported).

Hypothesis 4a. A high level of technical implementation success is associated with a high level of data quality (not supported).

Hypothesis 4b. A high level of technical implementation success is associated with a high level of system quality (not supported).

Hypothesis 5. A high level of management support is associated with a high level of organizational implementation success (supported).

Hypothesis 6a. A strong champion presence is associated with a high level of organizational implementation success (not supported).

Hypothesis 6b. A strong champion presence is associated with a high level of project implementation success (not supported).

Hypothesis 7a. A high level of resources is associated with a high level of organizational implementation success (supported).
Hypothesis 7b. A high level of resources is associated with a high level of project implementation success (supported).

Hypothesis 8a. A high level of user participation is associated with organizational implementation success (supported).

Hypothesis 8b. A high level of user participation is associated with project implementation success (supported).

Hypothesis 9a. A high level of team skills is associated with project implementation success (supported).

Hypothesis 9b. A high level of team skills is associated with technical implementation success (not supported).

Hypothesis 10. High-quality source systems are associated with technical implementation success (supported).

Hypothesis 11. Better development technology is associated with technical implementation success (supported).

A valuable part of in this article (Wixom \& Watson, 2001) that even led to verifying the hypotheses proposed in this paper, was the statistical model using partial least squares regression. The resulting model can be seen in Figure

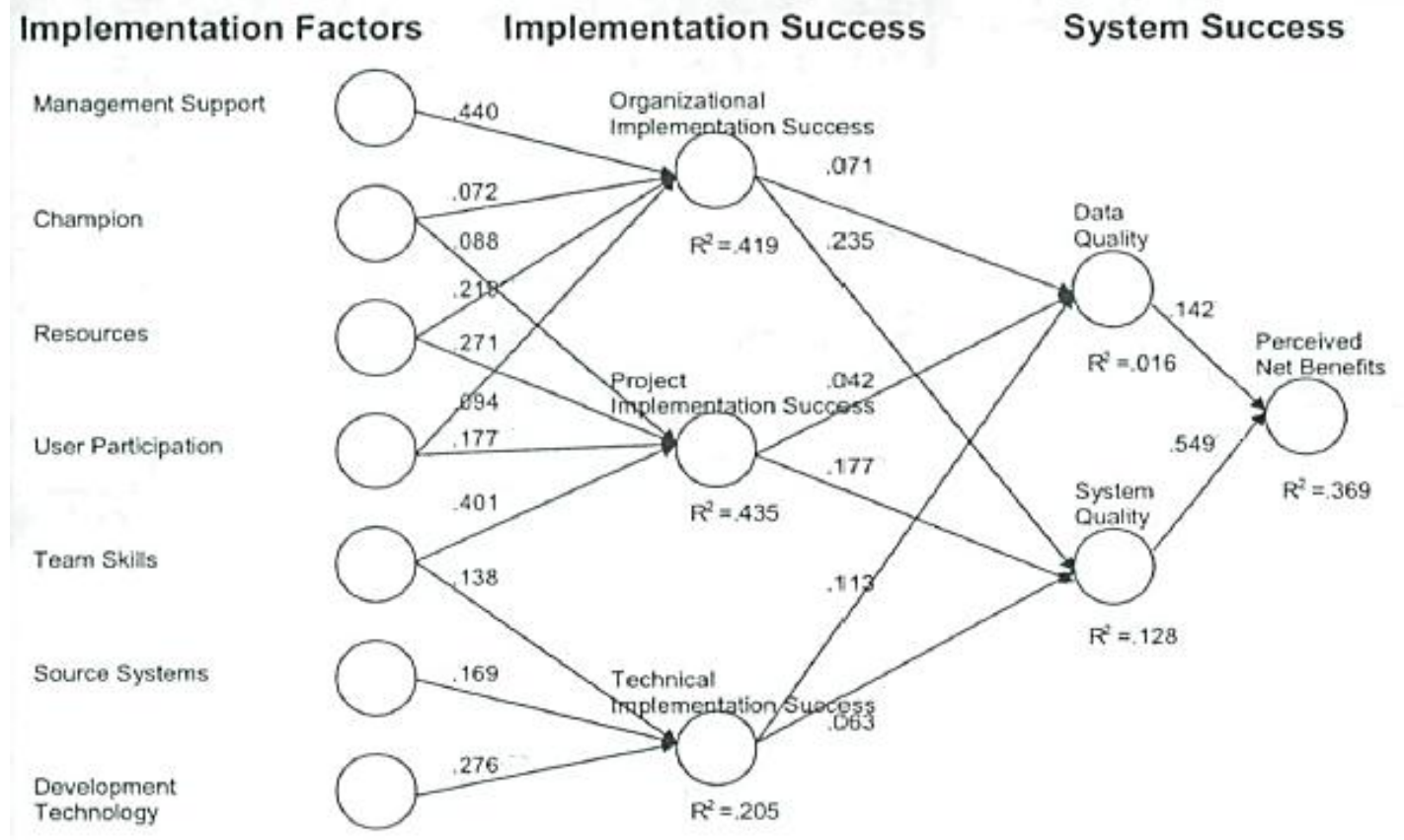

Figure 4: Wixom\&Watson statistical model of DW success (Wixom \& Watson, 2001)

$\mathrm{R}^{2}$ values obtained by Wixom and Watson (2001), (Figure 4) ranging between 0.016 to 0.435 , means that independent variables used in the model provide limited explanatory power for dependent variables. This makes it impossible to compare findings with our study. The model relies on the IS success model by Delone \& McLean (1992) which defines system success using a structure of proxy variables - data and system quality, and benefits. Variables used covered both technical and nontechnical factors influencing data warehouse implementation success. The way the model was 
constructed makes it impossible to verify whether technical or non-technical factors influence the success more strongly. The article (Wixom \& Watson, 2001) does not attempt to propose specific measurement criteria for the variables used.

\subsection{Current Practices in Data Warehousing}

The study conducted in the article of Watson, Annino, Wixom, Avery, \& Rutherford (2001) concentrated on some of the factors influencing data warehousing projects success. Survey respondents were asked to provide answers to questions about who sponsored the data warehouse, which organization unit was the driving force behind the initiative, about solution architecture and end users, about implementation costs, operational costs, solution approval process, after implementation assessment, realization of expected benefits (together with expectations). To describe success, two questions were used, one about ROI and the other about perceived success of implementation.

Although the authors gathered enough data to analyze the dependency of individual factors with success or to build a statistical model of several variables, they chose not to do so. Instead, they analyzed individual questions, summarizing contemporary practices. Findings say that most data warehouse sponsors come from business units and no single architecture dominates all implementations (Watson, Annino, Wixom, Avery, \& Rutherford, 2001). Because of the lack of a proposed framework, it is impossible to compare this article with our findings. Also, the article did not attempt to propose any objective measurement methods for variables included in the study.

\subsection{Measuring User Satisfaction with Data Warehouses: An Exploratory Study}

The study of Chen, Soliman, Mao, \& Frolick, (2000) uses end user satisfaction as a proxy for success and examines factors influencing the aforementioned user satisfaction. Study results identify three factors comprising several questions each. Those factors are: support provided to end users, accuracy, format and preciseness of data, and fulfillment of end user needs. Authors did not propose a framework for success and did not attempt to build a statistical model. They also did not attempt to develop objective and universal measurement methods for the variables identified.

Treatment of end user satisfaction as a proxy for project success and the goal to identify only the factors that influence this variable makes it difficult to compare the results with the findings. The authors (Chen, Soliman, Mao, \& Frolick, 2000) claim to have relied on the model of IS success (Delone \& McLean, 1992), but included only one of the "use" variables presented in that study. The study treated use as a whole and positioned it as one of the factors influencing success. It is impossible to tell whether technical or nontechnical factors are more important to project success following this article (Chen, Soliman, Mao, $\&$ Frolick, 2000) and no objective measurement methods are proposed.

\section{Empirical Data}

For primary research, surveys were used and 68 fully completed surveys obtained. The results were analyzed using quantitative methods - simple statistics (mean, mode, median) performed on individual questions, correlation analysis of individual variables with the dependent variable of success and Partial Least Squares Regression (PLS$\mathrm{R})$ used to build the target framework. Internetbased e-surveys were used.

Each single data point / measurement was a distinct Business Intelligence project. This implies that several measurements could have been obtained from a single vendor, customer or individual, provided that each of those measurements described distinct projects. Each survey contained optional questions about customer and vendor company names, project names, place where the project was performed as well as whether the survey participants were involved in a project on the customer or vendor side, and a precise project role of the participants.

Initial secondary research revealed that some of independent variables chosen by authors are correlated. Because of this and the fact that we aimed at analyzing direct dependency of all independent variables with success, there was a very high probability of multicollinearity in the data. For this reason, a method of data analysis insensitive for multicollinearity had to be chosen. Also, because of high number of independent variables chosen based on phase 1 findings and relatively low number of observations obtained through the survey, an appropriate method had to be chosen. Both requirements combined were satisfied by Partial Least Squares regression, a method that "was designed to deal with $(\cdots)$ regression when data has small sample, missing values, or multicollinearity" (Pirouz, 2006).

After completing the primary research, we propose our own framework for BI initiatives success, using prior research as a starting point. The framework was separated from the measurement methods to maintain the flexibility and applicability of the framework in various contexts. However, measurement methods were also proposed. Keeping those two separated will allow any future studies to propose different measurement for the variables. Also, a fact of 
importance is that it is much easier to combine a theoretical framework with specific measurement methods if they are kept separated, than to split them if they are merged in a single framework. Therefore, we decided to separately propose a theoretical framework and a specific measurement method for each of the variables.

\section{Analysis and Implications}

As mentioned, this study excludes trying to define what BI project success looks like. Instead, to determine whether a project is successful or not, the following interpretation from the survey results have been made throughout the article.

- Successful project/initiative - Project with answers "definitely yes" and "rather yes " to the question Q19:1 - "Was the project you are describing successful?"

- Non-successful project/initiative - Project with answers "neutral" , "rather no" and "definitely no" to the question Q19:1 - "Was the project you are describing successful?" . That is, non-successful means unsuccessful or neutral.

The reason behind such a distinction is that this article aims for developing tools that managers could use to achieve success. Merely avoiding failure is not good enough. If the project failed to achieve success, it cannot be treated as a mild success or neutral. Instead, it should then be considered as a non-successful project.

Results from the survey indicate that the funding of successful initiatives and non-successful ones differs. Successful initiatives are more likely to be funded in a phased approach, with separate budgets for each iteration, while the non-successful tend to be funded in a traditional way as other IT projects, i.e. one budget for the entire project.

Iterative development is used by both successful and non-successful initiatives, but results from the survey show that for an overwhelming majority $(89 \%)$ of the successful initiatives, each of the iterations provided business value by themselves. This can be compared to the non-successful initiatives that used an iterative approach, where every other initiative had iterations that provided value by themselves.

A BI solution designed with end users in mind will naturally have a greater usage than BI solutions that don' $t$ consider the end users. A whopping $96 \%$ of the successful initiatives in this study have users that actually use the Business Intelligence solution. The results for the nonsuccessful ones vary.

The presence of an overarching, clear strategic vision for Business Intelligence within the organization is important for the success of an initiative. Results show that successful initiatives exist in an environment with a clear strategic vision to guide the initiative as compared to nonsuccessful ones. A total of $81 \%$ of the successful initiatives agrees to this compared to $46 \%$ of the non-successful.

Not only is the existence of a strategic vision for Business Intelligence important, the business need that the initiative tries to solve should be aligned to that vision. Like the results for the existence of vision, the successful initiatives have business needs that tend to be more aligned with the strategic vision than for non-successful ones. $73 \%$ of the successful initiatives agree to that. Corresponding figure for the non-successful initiatives is $39 \%$.

The survey shows that successful initiatives often concentrate on choosing the best opportunities for the project scope. $57 \%$ of the surveyed successful initiatives do this, compared to $23 \%$ of the non-successful ones.

Another parameter measured by the study is whether an expert assigned to a team or made available to a team, always was the best expert available. The results from the study reveal, somewhat surprisingly, that non-successful initiatives to a larger extent assigns the best expert available, with $85 \%$. Corresponding number for the successful ones are $54 \%$.

Issues will occur during the duration of an initiative, which can be both technological and non-technological in nature. Both successful and non-successful initiatives do, to some extent, encounter non-technological issues, with nonsuccessful encountering them slightly more often according to this study. The technological issues are commonly found in both successful and nonsuccessful initiatives, but they are somewhat more common in the non-successful initiatives $(77 \%$ compared to $63 \%$ reports presence of technological issues). For all initiatives in the study only slightly more than $20 \%$ found technology related problems to be the hardest.

Consultants spend time on solving different kinds of problems, technological as well as nontechnological and for a majority of the initiatives a larger part of the time is spent on resolving nontechnological problems. This is especially true when looking at the non-successful initiatives, which show that almost $40 \%$ of the surveyed initiatives indicated that non-technological issues took the most time.

\subsection{A Statistical model of Business Intelligence initiatives' success.}

The survey results were analyzed using the Partial Least Squares regression method. Two separate series of models were built, one using original, 
untransformed data and the other, using the data transformed by centering on mean, dividing by a factor and applying basic mathematical functions. More details, and the rationale for performing those transformations, are provided later in the text.

The models built for original data analysis used 25 variables defined by answers to survey question $\mathrm{nr}$ 19. For the clarity of information presentation, variables were named after their respective survey questions - variable A19_1 corresponded to question 19:1 answers, A19_2 corresponded to question 19:2 answers and so on. Because question 19:1 asked users whether the project they described was successful, this variable was chosen as dependent for all the models, while every other variable was treated as independent.

Unlike other linear regression methods, adding more variables does not necessarily imply an increase of model' $\mathrm{s} \mathrm{R}^{2}$ when PLS is being used. The method cannot be used to eliminate insignificant variables, which is easily achieved in other linear regression methods. Therefore, the model that used all the available variables was not necessarily the best. Because the method cannot eliminate insignificant variables by setting the linear combination coefficients to 0 (or even close to 0 ), models that used only some of the variables were built.

Choice of variables that explain success should be made based on the individual independent variables' correlation with the dependent variable. After some experimentation, 5 variables with correlation of success stronger than 0.4 were chosen (absolute value of correlation coefficient greater than 0.4 ).

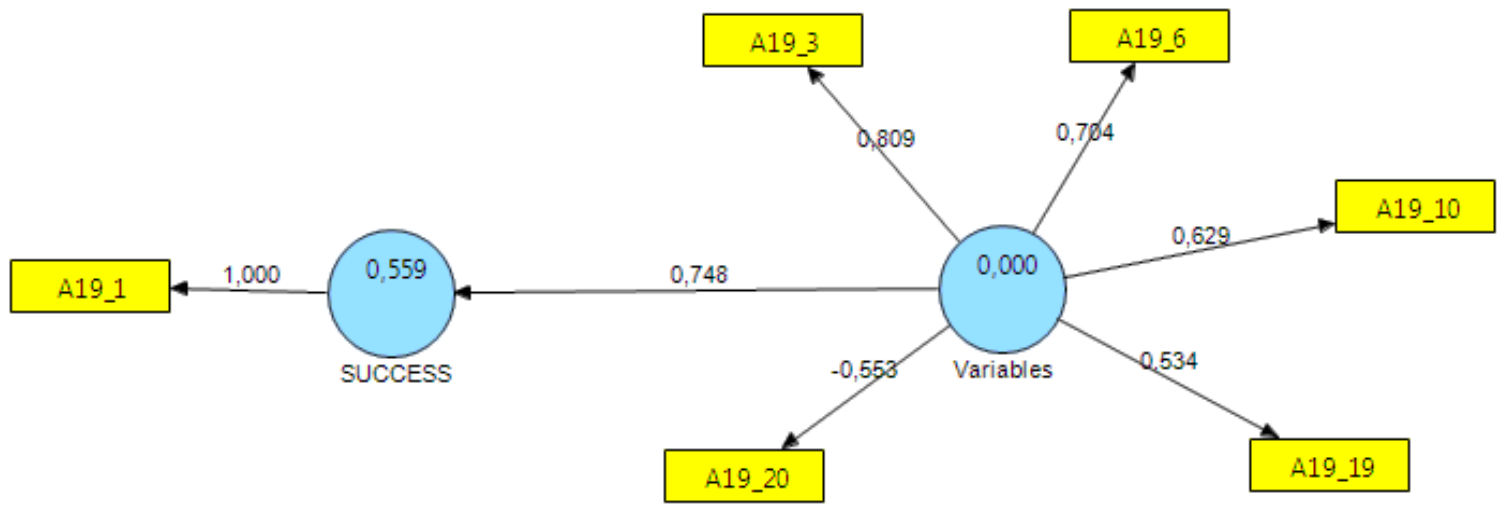

Figure 5: PLS regression model with 5 significant variables

As can be seen the model achieved a $\mathrm{R}^{2}$ of 0.559 , with changes in independent variables explaining $55.9 \%$ of changes in dependent variable. The variables that enabled these results were obtained as answers to the following questions:

Question 19_3. Did the end users use the data warehouse / BI solution provided?

Question 19_6. Were the business needs that project tried to solve aligned to the abovementioned strategic vision?

Question 19_10. Did project scope definition concentrate on choosing the best opportunities ("low-hanging fruit")?

Question 19_19. If technological issues were present, were all of them resolved?

Question 19_20. Were non-technological issues encountered during the project?

PLS is a linear regression method, but it is most likely that a dependency of success from the factors is not linear. The possibility of other dependencies had to be explored. While other, non-linear regressions could possibly be applied, a lack of any knowledge of the nature of the dependency would imply the need to try all of them, which was clearly beyond the scope of this study. Instead, linear regression could be applied to the transformed factors. For example, if linear regression could be done on squared factors, the outcome would be a case of square regression for the original factors; if various powers could be applied to these factors, the outcome would be polynomial regression and so on.

It is always possible to choose a function that will fit the given finite, discrete data set. To avoid such a pitfall, the transformations had to be limited to basic mathematical functions - power (including square root), logarithm, exponential functions, reciprocal or simple composition of aforementioned functions. Similar selection criterion as for original data applied, but the transformation had to improve the data. The transformed data was considered better than original if for a given function $\mathrm{f}$ and variable $\mathrm{x}, \mathrm{f}(\mathrm{x})$ had a stronger correlation with success than variable $\mathrm{x}$ itself. 
Before the abovementioned functions could be applied, initial data transformations were necessary. The data was centered on mean and divided by a factor to produce more distinct values instead of the same 5 values for all questions. None of those operations changed the correlation of data prior to applying the functions.

Based on the experience from model 1, the variables were sorted by correlation. To facilitate experimenting with the data model, a relative rank of correlation value was included in variable name while keeping the question number embedded. For example, variable V05_N19_20 had the fifth strongest correlation of all variables (05 in the name) and was a result of applying transformation ( $\mathrm{N}$ in the name) to question Q19:20 answers (19_20 in the name). For some variables, an alternative version of the same variable was also used. For example V18b_A19_15 was an alternative variable to V18a_N19_15, containing answers to question Q19:15 without applying the function, with only the transformations described in data preparation section above. The decision on whether to include an alternative variable or not was made based on how much the correlation has improved as a result of applying a given function, with 0.05 as a threshold. However, models containing alternative versions of the variables were not any different from those using transformed variables and will not be presented here. The summary of functions applied to variables is presented below:

- V01a_N19_3: q19_3 transformed using $\log (2,1-\mathrm{X} / 4)$

- V02_N19_6: q19_6 transformed using power(X, 3)
- V03_N19_6: q19_19 transformed using power(X, 3)

- V04_A19_3: q19_10 transformed using X

- V05_N19_20: q19_20 transformed using 1/power(2,X)

- V06a_N19_5: q19_5 transformed using $\exp (\mathrm{X})$

- V07_N19_18: q19_18 transformed using $1 /$ power(2,X)

- V08_N19_22: q19_22 transformed using $\exp (\mathrm{X})$

- V09_N19_25: q19_25 transformed using $\operatorname{sqrt}(\operatorname{abs}(\mathrm{X}))$

- V10N19_17: q19_17 transformed using 1/power(X,3)

- V11_N19_8: q19_8 transformed using $\operatorname{sqrt}(\operatorname{abs}(\mathrm{X}))$

- V12a_N19_16: q19_16 transformed using $1 /$ power(2,X)

- V13_N19_14: q19_14 transformed using $1 / \mathrm{X}$

- V14_N19_2: q19_2 transformed using $\operatorname{sqrt}(\operatorname{abs}(\mathrm{X}))$

- V15a_N19_12: q19_12 transformed using 1/power(X,3)

- V16_N19_7: q19_7 transformed using power(X, 2)

- V17_N19_11: q19_11 transformed using $1 /$ power(X,3)

- V18a_N19_15: q19_15 transformed using power(X, 3)

- V19_N19_24: q19_24 transformed using $1 / \mathrm{X}$

- V20_N19_23: q19_23 transformed using $1 / \mathrm{X}$

- V21_N19_9: q19_9 transformed using $\operatorname{sqrt}(\operatorname{abs}(\mathrm{X}))$

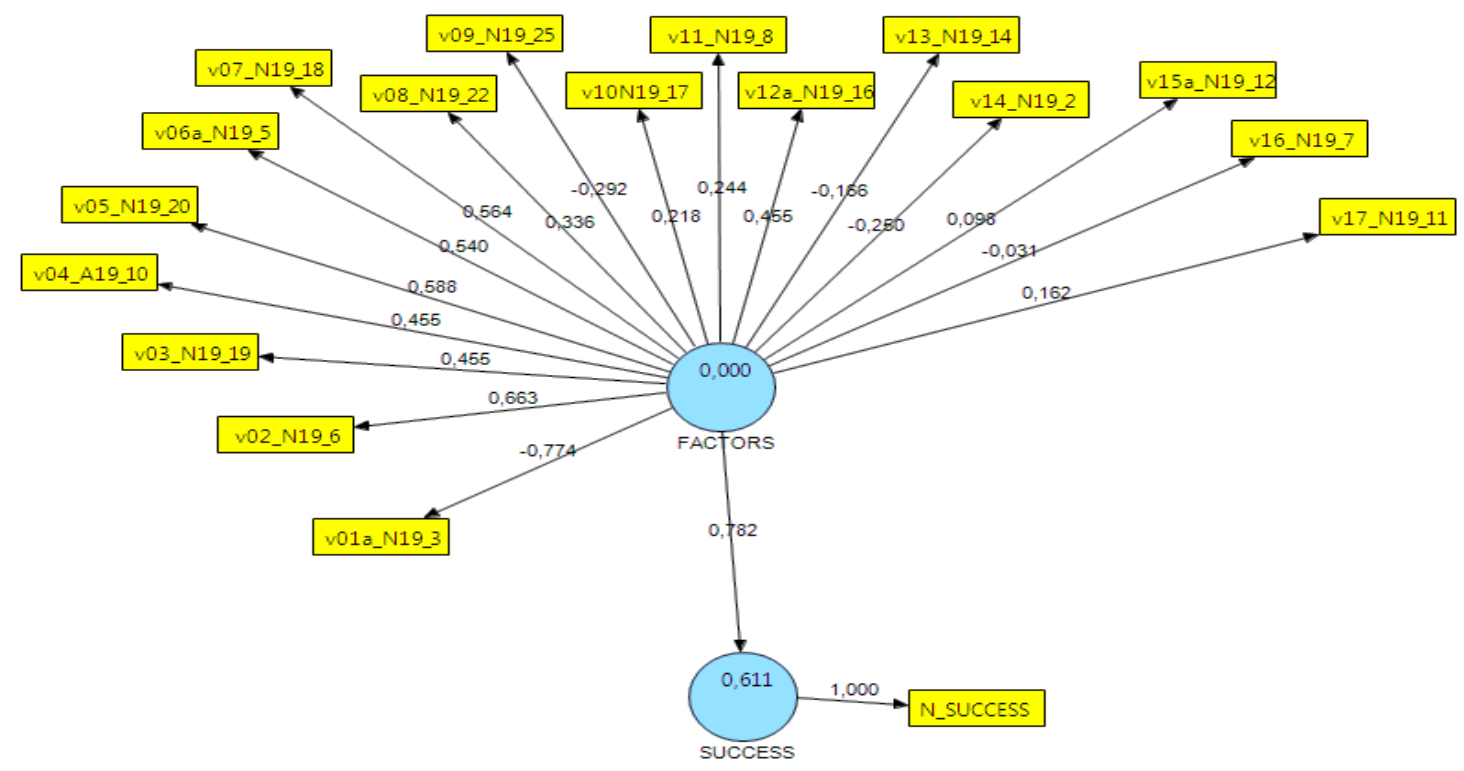

Figure 6: PLS regression model 2 - equivalent of model 1 with transformed variables 
In case of untransformed variables, the regression model with the best fit used only 5 independent variables. Therefore, the analogical model was tried using transformed data. This time, the improvement in $\mathrm{R}^{2}$ was smaller and the model was able to explain 0.584 of the success. The resulting regression model is presented in Figure 6 above.

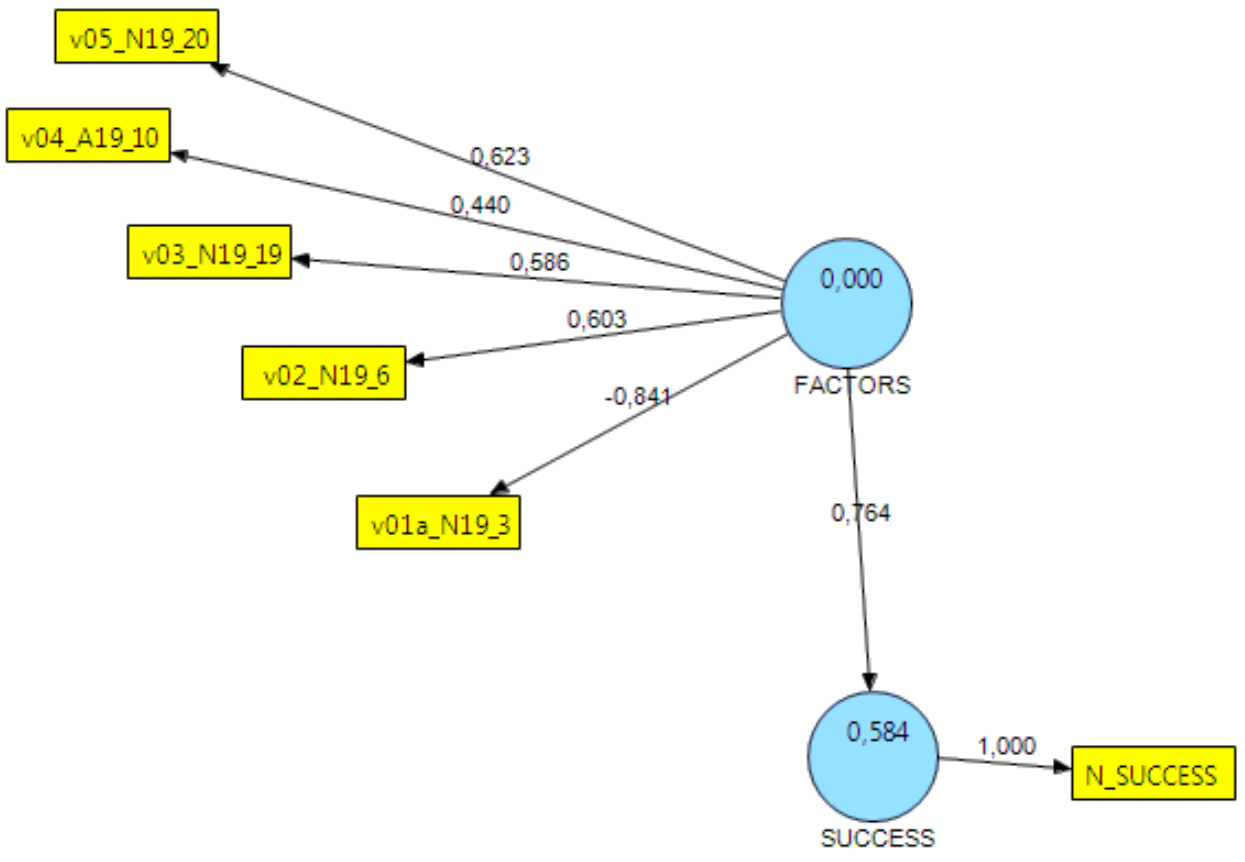

Figure 7: PLS regression model with the best fit

After some experimentation with various different models, $\mathrm{R}^{2}=0.611$ was achieved by one of them. It is presented in Figure 7. This was the best model found using either transformed or untransformed data. The variables used in this model are summarized as follows:

- V14_N19_2: Overall, was it possible to define factors that were critical to how successful the project was?

- V01a_N19_3: Did the end users use the data warehouse / BI solution provided?

- V06a_N19_5: Was there a clear strategic vision for Business Intelligence or data warehouse?

- V02_N19_6: Were the business needs that project tried to solve aligned to the abovementioned strategic vision?

- V16_N19_7: Was project's underlying business case preceded by a business needs analysis? This does not mean your party (vendor or customer) performed this analysis as part of the project

- V11_N19_8: Did the final solution evolve beyond initial scope? In case a program was established, answer on a program level
- V04_A19_10: Did project scope definition concentrate on choosing the best opportunities ("low-hanging fruit")?

- V17_N19_11: When an expert in a particular field was needed, was project team always granted access to an expert or enhanced by including one?

- V15a_N19_12: When an expert was assigned to a team or made available to a team, was it always the best expert available?

- V13_N19_14: If there were data quality issues at source systems, were they known before the start of BI initiative?

- V12a_N19_16: Were there data quality issues in BI system or data warehouse?

- V10N19_17: Were data quality issues in BI system or data warehouse eventually resolved?

- V07_N19_18: Were technological issues encountered during the project?

- V03_N19_19: If technological issues were present, were all of them resolved?

- V05_N19_20: Were non-technological issues encountered during the project?

- V08_N19_22: Data architecture was performed at the beginning of BI initiative (note - data architecture is different from 
systems architecture or solution architecture)

- V09_N19_25: Was there a process in place to measure business benefits?

\subsection{Measures Analysis}

From the three measures of data warehouse use proposed in the survey, none were found bad or even rather bad. Conversely, none of them were found definitely good. The best from the three was a weekly number of queries. The fact that it was positively evaluated in most responses and that mean value was close to being rather good makes this measurement method adequate and fairly universal. It is objective and can be automatically computed.

Out of the two proposed measurement methods of access to subject matter experts, respondents found both "rather good", with over two thirds of respondents agreeing with this view. Despite the fact that the mean response time turned out to score slightly better, we propose to use both as measurement for the "access to subject matter experts"- variable. To compute any of them, a formal process of request tracking should be made, but with this process in place, both measures are objective and easy to compute.

Only one of the three proposed measurement methods for subject matter expert quality was found applicable. It turned out to be the same measurement method as for the access to subject matter experts. Because of that, the same arguments about measurement method objectivity and computability apply.

From the three measures proposed in the survey for the question of whether there was enough business staff on the project, we found that both percentages of business issues resolved within a business week. The mean time to resolve a business issue qualify as an adequate measure for the variable was there enough business staff on a project. We found little difference in those measures as they are equally good and equally objective. They are both calculated in a similar way therefore either one of them could be used, or even both at the same time.

Two measures of deliverable size in iterative development were proposed and we found that only a percentage of total project time for each iteration is a good one. However, this measure is only objective after the project ends. It can be calculated during the planning phases and project schedule can be used for that purpose. Unfortunately, this makes the measure less objective and easy to manipulate. This diminishes its applicability to predict initiative success. Despite these drawbacks, we postulate to use this measure in absence of better alternatives. Perhaps other measures could be examined in the future to replace this one, for instance percentage of total budget allocated or a similar measure.

Out of three measures proposed for data quality issues at source systems, it was found that both counting the total number of issues and the number of unresolved issues are adequate and almost identically rated. Therefore no distinction can be made as to which one of them to use and we recommend using both. They should be easily computable if only the formal issue tracking process is in place. However, both measurement methods can only be used after the project end as the number of issues is unpredictable (following our earlier findings, a number of issues were discovered during the BI project). For this reason it would be hard to predict initiative success based only on the upfront knowledge about source systems data issues.

From the three measurement methods proposed for data quality issues in BI system or data warehouse, no one better than the others were found. Therefore, it is conclude that this variable should be measured using the number of unresolved issues. The fact that this variable could be objectively measured only after the project ends makes it unsuitable for use in predicting project success.

All three measurement methods proposed for benefits quantification were found adequate for quantification. Both ROI and IRR calculations were objective yet difficult to perform at project start, while relating capabilities to company strategy was less objective but easier to apply early in the project. It would be best if financial indicators could be calculated at project start; therefore those two methods would be preferred over the one called strategy, however all three are worth using and will probably work in practice.

Both measurement methods proposed for business benefits definition were evaluated positively by survey respondents with percentage of business benefits objectively measureable being significantly better than just a written definition of the benefits. Both were objective and computable in the early stages of the project. Although, percentages were recommended as a better measurement, we also note that both are likely to be used in practice as it is unlikely that a company will have the benefits that are measureable without first defining them. Therefore, in practice, when the better measurement method can be applied, then so can the one that is worse off.

From the two measurement methods proposed for business benefit measurements, only one was approved by survey respondents - the presence or absence of business benefits process owner. This measurement process can and should be used in predicting the project success. 


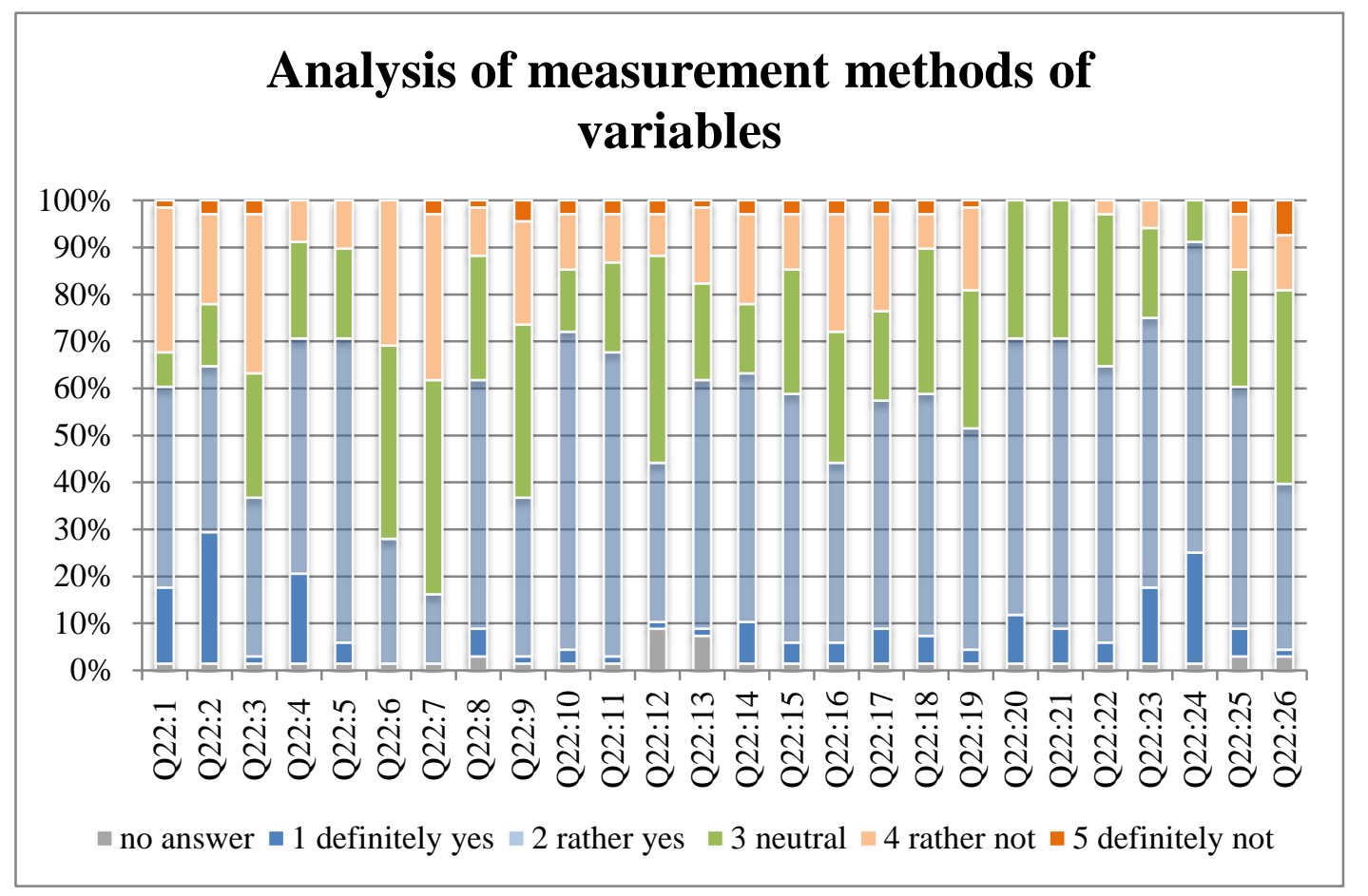

Figure 8: Analysis of measurement methods of variables (Q22)

For each of the variables analyzed in question 22, there was at least one measure that was deemed good enough to be generally used for all projects. However, almost no measure was found definitely good. There are two possible explanations for this phenomenon. Either there is no universally acceptable measurement method for those variables or such a variable exists but was not discovered in this study. Neither of the above possibilities can be verified using data gathered in this study.

\section{Hypotheses Analysis}

Hypothesis 1 (first part). It is possible to identify critical success factors (CSFs) of BI initiatives in large enterprises.

To determine if factors exist that, if present, are more likely to lead to initiative success, an analysis of the correlation between the success and different factors surveyed was performed. To demonstrate causality, the statistical evidence of correlation between success and different key success criteria are complemented with an argumentation on what the casual relationship is. To show correlation between different criteria and the success of the initiatives, Spearman's rank correlation coefficient (Spearman's $\rho$ ) was chosen. Motivation for choosing Spearman's rank correlation coefficient includes that it does not require the relationship to be linear, but also the fact that it is often used for Likert scales data sets in e.g. medicine, biochemistry and other sciences with success (Jamieson, 2004). The questions/factors with correlation coefficients with an absolute value of 0.25 or higher are (correlation coefficient in parenthesis):

- Did project scope definition concentrate on choosing the best opportunities ("lowhanging fruit")? $(0,43)$

- Were non-technological issues encountered during the project? $(-0,42)$

- Were the business needs that project tried to solve aligned to the abovementioned strategic vision? $(0,41)$

- Was the project meant to address specific business needs of the sponsor? $(0,38)$

- Data architecture was performed at the beginning of BI initiative $(0,37)$

- Was there a clear strategic vision for Business Intelligence or data warehouse? $(0,35)$

- Were there data quality issues at source systems? $(-0,30)$

- If iterative development was chosen, did each iteration provide business value by itself or in connection with previous deliverables? $(0,29)$

- Were technological issues encountered during the project? $(-0,28)$

- Were data quality issues in BI system or data warehouse eventually resolved? $(0,27)$

- Have business benefits been quantified? $(0,26)$ 
From the above it can be conclude that there are in fact criteria (those factors with a large correlation with success of the initiative) that, when present, are associated with a higher likelihood of initiative success.

Hypothesis 1 (second part). CSFs of BI initiatives are not the same as for other IS in large enterprises.

Looking at the top criteria for successful initiatives with the highest ranking from the surveyed participants shows that success factors related to the project actually addressing a specific business need is most important. Building a solution that is tailored to user requirements and therefore enables usage of the Business Intelligence solution is also important. In the third place comes; documenting success criteria for the initiative early on in the initiative.

Resolving technological issues, having a clear vision to guide the initiative and including a business need analysis early on are other important criteria. The survey clearly shows that nontechnological factors rank high amongst the answers. To compare this to success factors for IS in general, a framework proposed by Delone and McLean (Delone \& McLean, 1992; 2003) was used. The original framework proposed by these authors has been updated with an updated version (Delone \& McLean, 2003). As discussed previously the factors leading to the success of IS project in general include information quality, system quality and service quality. The first thing that strikes one in the framework proposed by Delone and McLean is the heavy focus on technical issues and factors, and little to none concentration on the softer factors that pertain to management issues.

One difference from the general IS framework proposed by Delone and McLean and the findings from this study is the addition of more nontechnical factors such as the presence of a specific business need to be addressed by the initiative, a clear vision to guide the initiative and a preinitiative definition of success factors.

Hypothesis 2. Non-technical and nontechnological CSFs play a dominant role in BI initiatives' success in large enterprises.

From what has been seen earlier, most of the CSFs with high correlation with success are in fact nontechnical. Examples are:

1. Successful initiatives do focus, to a larger extent, on choosing the best opportunities i.e. "low-hanging fruit" or quick wins.
2. Successful initiatives are more likely to have a clear strategic vision for Business Intelligence or data warehouse.

3. Successful initiatives are more often meant to address a specific business need of the sponsor.

4. The business needs addressed by successful initiatives are more often aligned with the abovementioned strategic vision.

Looking at individual CSFs and the responses from the survey, one can see that for non-technical issues, there is a noteworthy difference between the results for successful initiatives and the nonsuccessful ones.

One example of this is the area of iterative development. For those initiatives that used an iterative approach, each iteration was more likely to provide business value by itself for the successful ones. A total of $89 \%$ agreed to this, compared to $50 \%$ for the non-successful initiatives.

Another example concerns the presence of a strategic vision for Business Intelligence. A total of $81 \%$ of the successful initiatives had a clear strategic vision compared to only $46 \%$ of the nonsuccessful ones.

In conjunction with the presence of a strategic vision for Business Intelligence as a whole, the successful initiatives are more likely to address a specific business need that is aligned to this strategic vision. Some $73 \%$ of the successful initiatives were addressing a specific business need aligned with the strategic vision. This is almost twice as common as the $39 \%$ of the non-successful ones.

When looking at the scope definition, the successful initiatives are more often concentrating on choosing the best opportunities as depicted by the chart below. $57 \%$ of the successful initiatives do this compared to the non-successful ones $23 \%$.

All of the above examples are non-technical factors that are (to a varying degree) more commonly found in successful initiatives than those initiatives that fail. This in turn, indicates that non-technical and non-technological CSFs play a dominant role in BI initiatives' success in large enterprises.

Hypothesis 3. Technology plays a secondary role and is less critical for BI initiatives' success in large enterprises

The results from the survey show clearly that nontechnical factors were the hardest to solve. Results show that for all initiatives in the survey only slightly more than $20 \%$ found the technology related problems to be the hardest to solve. The fact that the non-technology related problems were harder to solve is even more evident when looking at the non-successful initiatives only, where almost 
as many as $70 \%$ of the initiatives found the nontechnology related problem to be the hardest.

Another view on this is the time spent on the different types of problems. Again, as we can see a larger part of the time is spent on resolving nontechnological problems. This is especially true when looking at the non-successful initiatives, out of which almost $40 \%$ indicate that nontechnological issues took the most time.

When comparing the successful initiatives with the non-successful ones and the presence of non-technological issues, it is clear that the initiatives that fail more often encounter nontechnological problems. One interpretation of this could be that the presence of non-technological issues will have a detrimental effect on the likelihood of initiative success.

Hypothesis 4. It is possible to develop objective measures for each of CSFs of BI initiatives in large enterprises.

The result of this study shows that all the CSFs clearly have one or more measures that are ranked higher than the rest. The following summarizes the proposed measurements methods resulting from the survey.

\begin{tabular}{|c|c|}
\hline Area/Variable & Proposed method(s) \\
\hline $\begin{array}{l}\text { Data warehouse } \\
\text { use }\end{array}$ & - Weekly number of queries submitted \\
\hline $\begin{array}{l}\text { Access to subject } \\
\text { matter experts }\end{array}$ & $\begin{array}{l}\text { - } \quad \text { Percentage of requests responded within one business day } \\
\text { - } \quad \text { Mean response time for a request }\end{array}$ \\
\hline $\begin{array}{l}\text { Subject matter } \\
\text { expert quality }\end{array}$ & $\begin{array}{l}\text { - Average number of questions needed to be asked per subject } \\
\text { matter issue } \\
\text { - } \quad \text { Average number of available documents per subject matter issue } \\
\text { - Percentage of questions answered within one business day }\end{array}$ \\
\hline $\begin{array}{l}\text { Adequate level of } \\
\text { business staff on } \\
\text { the project }\end{array}$ & $\begin{array}{l}\text { - } \quad \text { Percentage of business issues resolved within a business week } \\
\text { - } \quad \text { Mean time to resolve a business issue }\end{array}$ \\
\hline $\begin{array}{l}\text { Size of } \\
\text { deliverable in } \\
\text { iterative } \\
\text { development }\end{array}$ & - $\quad$ Percentage of total project time for each iteration \\
\hline $\begin{array}{l}\text { Data quality } \\
\text { issues at source } \\
\text { systems }\end{array}$ & $\begin{array}{ll} & \text { Total number of issues } \\
\text { - } & \text { Number of unresolved issues }\end{array}$ \\
\hline $\begin{array}{l}\text { Quality issues in } \\
\text { BI system or data } \\
\text { warehouse }\end{array}$ & - $\quad$ Number of unresolved issues \\
\hline $\begin{array}{l}\text { Benefits } \\
\text { quantification }\end{array}$ & $\begin{array}{l}\text { - Calculated ROI } \\
\text { - Proposition on how the business intelligence capabilities enables } \\
\text { the realization of business strategy } \\
\text { - } \quad \text { Contribution to the internal rate of return }\end{array}$ \\
\hline $\begin{array}{l}\text { Business benefits } \\
\text { definition }\end{array}$ & - Percentage of business benefits that are objectively measureable \\
\hline $\begin{array}{l}\text { Business benefits } \\
\text { measurements }\end{array}$ & $\begin{array}{l}\text { - Presence or absence of business benefits measurements process } \\
\text { owner }\end{array}$ \\
\hline
\end{tabular}

Table 1: Summary of variables analysis

\section{Conclusions}

The hypotheses of this study are focused on the factors that make Business Intelligence initiatives successful.

A quantitative approach was used to gather data to support or reject the above hypotheses and a primary research survey was used for gathering data on the above hypotheses. The survey was conducted online during Q2 of 2011. The findings can be summarized as follows.

\subsection{Non-technological problems dominate in Business Intelligence projects}

Business Intelligence projects wrestle with both technological and non-technological problems, but the non-technological problems are found to be 
both harder to solve sand more time consuming than their technological counterparts. For all initiatives in the survey, only slightly more than $20 \%$ found the technology related problems to be the hardest. When looking at the non-successful initiatives only, almost as much as $70 \%$ found the non-technology related problem to be the hardest. The other view on this, the time spent on the different types of problems, also shows that a larger part of the time is spent on resolving nontechnological problems. This is especially true when looking at the non-successful initiatives, almost $40 \%$ of which indicate that nontechnological issues drove the most time.

\subsection{Successful projects share common factors}

Certain factors or attributes of Business Intelligence projects are correlated with the success of the initiative. The correlation has been calculated using Spearman's rank and shown in the model that was developed using Partial Least Squares. By using rational argumentation, it can be shown that those factors do in fact have a causal relationship with the likelihood of success. The highest correlated factors are:

- A project scope definition that concentrate on choosing the best opportunities ("lowhanging fruit")

- The alignment of the business needs that project tries to solve aligned with the strategic vision of business intelligence

- A project that is meant to address specific business needs of the sponsor

- Performing data architecture at the beginning of BI initiative

- Having a clear strategic vision for Business Intelligence or data warehouse

6.3 Successful and non-successful projects show differences in certain factors

For a number of different factors, clear differences can be observed for successful and non-successful initiatives. This shows that successful initiatives are doing specific things more frequently than the nonsuccessful. Factors with great differences are:

- The type of funding of the initiative

- Business value provided by each iteration

- An alignment of the business needs that project tried to solve aligned to the strategic vision of Business Intelligence

- A project that is meant to address specific business needs of the sponsor

- A project scope definition that concentrate on choosing the best opportunities ("lowhanging fruit")
6.4 Business Intelligence project have success factors that differ from IS projects in general

Comparing the critical factors for BI projects that are correlated with success, or are otherwise more commonly found in successful initiatives, with the success factors for general IS projects found in literature shows that they do in fact differ. One of the major differences between the results found in this study is the focus on non-technological factors. One example of this are the frequently quoted papers by Delone and McLean (1992; 2003), that predominately discussed technological factors while the results of this study point to the nontechnological factors as being more important.

\subsection{Clear objective measures for CSFs can be identified}

Clear objective measures that are commonly agreed upon according to the survey exist for each of the CSFs analyzed in the survey. For some of the CSFs, the results are clearly pointing towards one of the suggested measures, while others can have multiple measures that claim to be equally good measures. However, due to practical reasons, to the limit of the survey size, measurements for only 10 variables were proposed. For the remaining variables, it is impossible to verify whether the remaining variables do or do not have objective measurement methods.

6.6 A statistical model can be constructed that, to a certain extent, predicts the success of BI projects

A critical success factors framework for Business Intelligence initiatives have been developed as part of this study. The results from the survey show that $61 \%$ of variability of success can be explained by changes in independent variables. Limiting the model to 5 independent variables (out of 17 that offer the highest explanatory power of the model) makes the model only slightly less powerful, allowing it to explain 58\% of success variability. A conclusion from this would be that managers need only to monitor properly and manage 5 factors to achieve better probability of success, than the $20 \%$ $50 \%$ currently achievable in Business Intelligence. For a Business Intelligence project to be successful:

1. Business Intelligence solution must be built with end users in mind, as they need to use it

2. The Business Intelligence system needs to be closely tied to a company' $\mathrm{s}$ strategic vision

3. Project needs to be properly scoped and prioritized to concentrate on best opportunities first 
4. Although technological issues are encountered, all of them need to be solved

5. Non-technological issues should be avoided as they can hinder the success of the BI initiative

Below is a summary of the support for the four hypotheses of this study.

Hypothesis 1. It is possible to identify critical success factors (CSFs) of BI initiatives and they are different from the CSFs of information systems in general. (supported).

Hypothesis 2. Non-technical and nontechnological CSFs play a dominant role in BI initiatives' success for initiatives (supported).

Hypothesis 3. Technology plays a secondary role and is less critical for BI initiatives' success for initiatives (supported).

Hypothesis 4. It is possible to develop objective measures for each of CSFs of BI initiatives primarily (partially supported - the survey did not cover measurement analysis all CSFs).

\section{Future research}

The survey data received describes project primarily from Poland and primarily from a vendor perspective. Conducting a similar research on a more generalized sample spanning projects worldwide with equal emphasis on vendors and customers would be an obvious next step. It would verify if the relationship between success and its factors is a phenomenon local to Poland or rather, as we suspect, general in nature.

Several other frameworks were reviewed in this study. A carefully constructed study with properly chosen variables would allow comparing each framework's validity with regards to contemporary Business Intelligence projects seeing if one is significantly stronger than the rest of them. This is not a trivial task, because of different treatment of success and its factors, using proxy variables for success or even modeling dependencies between various parts of a success.

The word critical in its strict mathematical meaning would suggest that if even one of critical success factors is missing, success cannot happen. Such a relationship is impossible to model using linear regression. Even the application of data transformation must be taken into account, similar to the achieved linear combinations of some functions of variables. Therefore, another study could be performed to search for a model that would better explain the success using the variables used by us. It is possible that the variables used in this study would be able to predict more of the Business Intelligence success when organized in a different fashion
Because almost $40 \%$ of success variability remains unexplained in this model, it is possible that it can be attributed to the weakness of the linear relationship assumed in the model, to the missing variable that remains unidentified or even to a random factor that is influenced only by chance and which cannot be controlled by management. Before a model with higher explanatory power is constructed, it is appropriate to keep looking for a missing variable that might potentially account for a significant portion of unexplained success variability.

Although this work proposes several objective measurement criteria for independent variables, most of them cannot be considered universally applicable in all (or even most) Business Intelligence projects. Therefore, another study could be conducted to verify whether such universal and objective measures exist and attempt to define them. In case such measures do not exist, perhaps there is a set of measures for each variable such that at least one of the quantification methods would be universally applicable.

One of the delimitations in this work was lack the treatment of NPV, ROI and other financial measures of Business Intelligence projects. Since success factors are different for BI than for IS in general, perhaps Business Intelligence managers could also employ different methods for calculating financial measures than in the case of other IS. In case such differences are identified, appropriate methods should be proposed and aforementioned differences should be uncovered.

\section{Refrences}

Adelman, S. 2003. Impossible Data Warehouse Situations. Solutions from the Experts. Boston, MA: Pearson Education.

Adèr, \& Mellenbergh, G. 2011. Advising on Research Methods: A consultant's companion. $3^{\text {rd }}$ ed. Huizen, The Netherlands: Johannes van Kessel Publishing.

Ariyachandra, T., \& Watson, H. 2006. Which Data Warehouse Architecture Is Most Successful? Business Intelligence Journal , 11 (1).

Babbie, E. 2009. The Practice of Social Research. Wadsworth Publishing.

Beal, B. 2005. Report: Half of data warehouse projects to fail. Retrieved May 22, 2011, from Search CRM: http://searchcrm.techtarget.com/news/1066086/ Report-Half-of-data-warehouse-projects-to-fail

Chen, L., Soliman, K., Mao, E., \& Frolick, M. 2000. Measuring user satisfaction with data warehouses: An exploratory study. Information \& Management, 37 (3), 103-110.

Daniel, D. 1961. Management Information Crisis. Harvard Business Review. 
Delone, W., \& McLean, E. 1992. Information Systems Success: The Quest for the Dependent Variable. Journal of Information System Research, 3 (1), 60-95.

Delone, W., \& McLean, E. 2003. The DeLone and McLean Model of Information Systems Success: A Ten-Year Update. Journal of Management Information Systems , 19 (4), 930.

Duncan, W. 1996. A Guide to the Project Management Body of Knowledge. Sylva, North Carolina: PMI Publishing.

Ellison, R., \& Moore, A. 2003. Trustworthy Refinement Through Intrusion-Aware Design. Carnegie Mellon Software Engineering Institute.

Garthwaite, P. 1994. An Interpretation of Partial Least Squares. Journal of the American Statistical Association , 89 (425), 122-127.

Hwang, M., \& Xu, H. 2008. A Structural Model of Data Warehousing Success. Journal of Computer Information Systems , 48-56.

Inmon, W. H. 2002. Building the Data Warehouse, 3rd ed. New York, NY: John Wiley \& Sons.

Jamieson, S. 2004. Likert scales: how to (ab)use them. Medical Education, 1217-1218.

Kimball, R., \& Ross, M. 2002. The data warehouse Toolkit, 2 ed. New York, NY: John Wiley and Sons, Inc.

Kimball, R., Ross, M., Thornthwaite, W., Mondy, J., \& Becker, B. 2008. The Data Warehouse Lifecycle Toolkit, 2nd ed. Indianapolis, IN: Wiley Publishing.

Laskowski, N. 2001. Gartner BI Summit: Business intelligence benefits lie in orchestration. Retrieved May 22, 2011, from http://searchbusinessanalytics.techtarget.com/ne ws/2240035533/Gartner-BI-Summit-Businessintelligence-benefits-lie-inorchestration?asrc=EM_NLN_13851353\&track $=\mathrm{NL}-544 \& \mathrm{ad}=832107$

Legodi, I., \& Barry, M.-L. 2010. The current challenges and status of risk management in enterprise data warehouse projects in South Africa. PICMET 2010 Technology Management for Global Economic Growth.

Linstone, H. A., \& Turoff, M. 2002. The Delphi Method Techniques and Applications.

Markarian, J., Brobst, S., \& Bedell, J. 2007. Critical Success Factors Deploying Pervasive BI.

Meehan, P. 2011. Patrick Meehan speech during Gartner Business Intelligence Summit 2011. London, UK. Retrieved from http://link.brightcove.com/services/player/bcpid 1156010110 ?bctid=741282639001

Merriam-Webster Dictionary. 2011. Retrieved May 24, 2011, from Merriam-Webster.com
Numminen, E. (2010). On the Economic Return of a Software Investment omManaging Cost, PhD Dissertation.

Pirouz, D. 2006. An Overview of Partial Least Squares. Retrieved May 27, 2011, from Social Science Research Network: http://ssrn.com/abstract=1631359

Pisello, T. 2001. IT Value Chain Management rom Social Science Research Network: htt Alinean, LLC.

Popovic, A., \& Jaklic, J. 2010. Benefits of Business Intelligence System Implementation: An Empirical Analysis of the Impact of Business Intelligence System Maturity on Information Quality.

Ringle, C., Wende, S., \& Will, S. 2005. SmartPLS 2.0 (M3) Beta. Hamburg.

Shin, B. 2003. An Exploratory Investigation of System Success Factors in Data Warehousing. Communications of the Association for Information Systems , 6 (4), 141-170.

Solberg Søilen, K., \& Hasslinger, A. 2009. How application integration, security issues and pricing strategies in business intelligence shape vendor differentiation. ECIS 2009: THIRD EUROPEAN COMPETITIVE INTELLIGENCE SYMPOSIUM, (pp. 252-260). Stockholm.

Walton, E. J., \& Dawson, S. 2001. Managers J., \& Dawson, S. MPETITIVE INTELLIGENCE SYMPOSIUMtrategiesJournal of Management Studies, 173-179.

Watson, H., Annino, D., Wixom, B., Avery, L., \& Rutherford, M. 2001. Current Practices in Data Warehousing. Information Systems Management, 18 (1), 47-55.

Wixom, B., \& Watson, H. 2001. An Empirical Investigation of the Factors Affecting Data Warehousing Success. MIS Quarterly, 25 (1), 17-41.

Yeoh, W., \& Koronios, A. 2010. Critical Success Factors for Business Intelligence Systems. Journal of Computer Information Systems, 50 (3), 23-32.

Yeoh, W., Gao, J., \& Koronios, A. 2007. Towards a CSF Framework for Implementation of Business Intelligence Systems: A Delphi Study in Engineering Asset Management Organisations. Research and Practical Issues of Enterprise Information Systems II. Beijing, PRC. 